\title{
Caracterização tecnológica da madeira de Cupressus lusitanica visando à produção de polpa celulósica
}

\author{
Magnos Alan Vivian ${ }^{1 *}$ (D), Ronan Corrêa ${ }^{1}$ (D), Karina Soares Modes ${ }^{1}$ (D), Ana Paula Caetano ${ }^{1}$ (D), Cristiane Pedrazzi ${ }^{2}$ (D), \\ Mário Dobner Junior ${ }^{1}$ (D)
}

${ }^{1}$ Universidade Federal de Santa Catarina, Rodovia Ulysses Gaboardi, km 3, CEP 89520-000, Curitibanos, SC, Brasil

${ }^{2}$ Universidade Federal de Santa Maria, Avenida Roraima, 1000, CEP 97105-900, Santa Maria, RS, Brasil

*Autor correspondente:

magnosalan@gmail.com

Termos para indexação:

Fibras

Celulose e papel

Anatomia da madeira

Index terms:

Fibers

Pulp and paper

Wood anatomy

Histórico do artigo:

Recebido em 21/01/2019

Aprovado em 24/04/2019

Publicado em 13/01/2020
Resumo - O estudo teve por objetivo determinar a composição química, densidade básica e parâmetros morfológicos dos traqueídeos da madeira de Cupressus lusitanica, visando verificar sua adequabilidade para produção de polpa celulósica. Foram utilizadas três árvores, com 16 anos, das quais extraíram-se discos que foram empregados na caracterização química, física e morfológica da madeira. A morfologia dos traqueídeos foi avaliada nos anéis correspondentes as idades 4, 7, 10, 13 e 16 anos. A partir dos parâmetros dos traqueídeos, calcularam-se os indicadores de qualidade da polpa. Foram observados baixos teores de cinzas e extrativos $(0,27$ e $2,13 \%$, respectivamente), porém alto teor de lignina $(32,52 \%)$. A densidade básica $\left(0,375 \mathrm{~g} \cdot \mathrm{cm}^{-3}\right)$ foi menor que de outras espécies de coníferas utilizadas para produção de celulose. Os traqueídeos apresentaram valores médios de 2,41 mm de comprimento; 31,40 $\mu \mathrm{m}$ de largura; $25,15 \mu \mathrm{m}$ de diâmetro do lúmen e 3,12 $\mu \mathrm{m}$ de espessura de parede, que tenderam a uma elevação nos valores com o aumento da idade. De maneira geral, a madeira de C. lusitanica apresenta boas características tecnológicas para produção de celulose e papel, especialmente pelos índices morfológicos de qualidade observados.

\section{Technological characterization of the wood of Cupressus Iusitanica aiming the production of cellulosic pulp}

\begin{abstract}
The objective of this study was to determine the chemical composition, basic density and tracheids morphological parameters of the wood of Cupressus lusitanica aiming to verify its suitability for cellulosic pulp production. Discs were collected from three 16-year-old trees to determine chemical, physical and morphological characteristics. The morphology of the tracheids was evaluated in the annual rings corresponding to the ages of 4, 7, 10,13 and 16 years. The pulp quality parameters were calculated from the tracheid parameters. The chemical composition indicated low ash and extractive contents ( 0.27 and $2.13 \%$, respectively), but high lignin content $(32.52 \%)$. The basic density $\left(0.375 \mathrm{~g} \mathrm{~cm}^{-3}\right)$ was smaller than other species of softwood used for pulp production. The mean values of tracheids dimensions observed were $2.41 \mathrm{~mm}$ of length, $31.40 \mu \mathrm{m}$ of width; $25.15 \mu \mathrm{m}$ of lumen diameter and $3.12 \mu \mathrm{m}$ of wall thickness, which tended to increase in values with increasing age. In general, C. lusitanica wood presents good technological characteristics for pulp and paper production, especially for the observed quality morphological index.
\end{abstract}




\section{Introdução}

O setor florestal brasileiro vem contribuindo de forma expressiva para a economia do país, gerando uma receita bruta de R \$ 86,6 bilhões em 2018, com aumento de $13,1 \%$ em relação ao ano anterior. Atualmente o Brasil conta com 7,83 milhões de ha de florestas plantadas, dos quais $36 \%$ são pertencentes a empresas do segmento de celulose e papel, mostrando a importância desse setor (Ibá, 2019).

Segundo a Indústria Brasileira de Árvores (Ibá, 2019), em 2018 o Brasil produziu 21,1 milhões de ton de celulose, considerando processos químicos e pasta de alto rendimento, um aumento de $8,0 \%$ em relação a 2017, colocando o país como o segundo maior produtor mundial de celulose.

Entre todos os processos para obtenção de polpa celulósica, o mais difundido no mundo é o kraft. Esse é um processo químico que apresenta inúmeras vantagens, como polpa de alta resistência e, principalmente, possibilidade de reutilização dos reagentes empregados no processo (Frinhani \& Daltoé, 2012).

O principal objetivo dos processos químicos é a separação da lignina dos carboidratos (celulose e hemicelulose), visando à individualização dos elementos celulares. Para que isso ocorra, é preparado um licor de cozimento, no qual estão presentes reagentes que agem na dissolução da lignina. No processo Kraft emprega-se o hidróxido de sódio $(\mathrm{NaOH})$ e o sulfeto de sódio $\left(\mathrm{Na}_{2} \mathrm{~S}\right)$ para tal reação (Favero et al., 2014).

A composição química e a densidade básica da madeira influenciam parâmetros do processo de polpação, como o uso de reagentes, quantidade de resíduos sólidos gerados no licor negro e rendimento de celulose (Gonçalez et al., 2014). A morfologia dos traqueídeos influencia diretamente nas características da polpa celulósica e do papel, sendo que folhas de papel constituídas por traqueídeos com dimensões diferentes proporcionam propriedades físicas e de resistência distintas (Andrade, 2006).

As espécies de Pinus são as principais coníferas utilizadas no mundo para fabricação de celulose de fibra longa, apresentando madeira com boas características tecnológicas para este fim. No Brasil a espécie de Pinus que se destaca para produção de celulose é o $P$. taeda L. Seus traqueídeos apresentam de 3 a $6 \mathrm{~mm}$ de comprimento, característica que confere maior resistência aos papéis e embalagens (Gomes, 2009).
No entanto, é importante a realização de estudos visando identificar novas espécies para inserção no mercado papeleiro, como alternativas para os segmentos de fibra curta ou de fibra longa. C. lusitanica vem se destacando no sul do Brasil, por apresentar rápido crescimento, bom desenvolvimento e baixa exigência em solos (Shimizu et al., 2011). Entretanto, ainda não se tem conhecimento aprofundado sobre as reais possibilidades de uso desta espécie para suprir a demanda do mercado papeleiro.

Dessa forma, o objetivo desse estudo foi avaliar a composição química, densidade básica e características morfológicas de traqueídeos da madeira de C. lusitanica, visando verificar sua adequabilidade para produção de polpa celulósica.

\section{Material e métodos}

\section{Coleta e caracterização do material}

Utilizou-se madeira de Cupressus lusitanica Mill., com 16 anos de idade, proveniente de um plantio experimental, localizado no município de Campo Belo

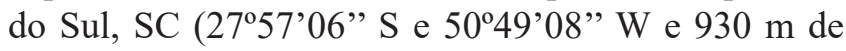
altura). O plantio apresentava espaçamento de 2,5 x 2,5 $\mathrm{m}$ (1.600 árv.ha $\left.{ }^{-1}\right)$, tendo recebido roçadas anuais nos dois primeiros anos, e desrama (poda) até $3 \mathrm{~m}$ de altura em 2 intervenções. O diâmetro médio a 1,3 $\mathrm{m}$ do solo (DAP) do povoamento era de $25,0 \mathrm{~cm}$ na ocasião da coleta das amostras.

Foram coletados discos do DAP de três árvores, que foram utilizados para a caracterização morfológica de traqueídeos, no Laboratório de Recursos Florestais, da Universidade Federal de Santa Catarina, localizado em Curitibanos, SC. A caracterização química e física da madeira foi conduzida no Laboratório de Química da Madeira, da Universidade Federal de Santa Maria, localizado em Santa Maria, RS.

\section{Caracterização química da madeira}

Para caracterização química da madeira foram utilizadas 2 cunhas simetricamente opostas por disco, que foram processadas em moinho tipo Willey. A serragem produzida foi classificada em peneiras vibratórias, tendo sido selecionada a fração de serragem retida entre as peneiras de 40 e 60 mesh. A serragem classificada dos três discos foi misturada, gerando uma amostra composta. 
Determinaram-se os seguintes parâmetros, em triplicata: teor de cinzas (TAPPI T211 om-02), teor de extrativos totais (TAPPI T264 cm-97, adaptada pelo Laboratório de Química da Madeira, UFSM), teor de lignina Klason (TAPPI T222 om-98), e teor de holocelulose (celulose e hemicelulose), obtido pela diferença dada pela Equação 1.

$$
H C=100-(T C+T E+T L)
$$

Em que: $\mathrm{HC}=$ teor de holocelulose $(\%) ; \mathrm{TC}=$ teor de cinzas $(\%)$; $\mathrm{TE}=$ teor de extrativos totais $(\%)$; $\mathrm{TL}=$ teor de lignina $(\%)$.

\section{Determinação da densidade básica}

A determinação da densidade básica dos cavacos da madeira de $C$. lusitanica seguiu o método do máximo teor de umidade, conforme descrito pela norma da Associação Brasileira de Normas Técnicas (ABNT) NBR 11941 (2003), a partir da média aritmética de 6 amostras de $200 \mathrm{~g}$ de cavacos cada (Equação 2).

$$
D B=\frac{1}{\frac{M U}{M S}-0,346}
$$

Em que: $\mathrm{DB}=$ densidade básica $\left(\mathrm{g} \cdot \mathrm{cm}^{-3}\right) ; \mathrm{MU}=$ massa úmida $(\mathrm{g}) ; \mathrm{MS}=$ massa seca $(\mathrm{g})$.

\section{Caracterização morfológica da madeira}

Os cortes transversais retirados do DAP foram primeiramente lixados, para na sequência serem delimitados os anéis de crescimento. Após, foi extraída, em serra circular, amostras centrais no sentido medulacasca. Nessas amostras, os anéis de crescimento correspondentes às idades de 4, 7, 10, 13 e 16 anos, foram selecionados para serem submetidos à maceração.

O processo de maceração foi realizado utilizandose solução de ácido acético, ácido nítrico e água, na proporção de 5:2:1, por um período de aproximadamente $1 \mathrm{~h}$ em banho-maria a uma temperatura de $100^{\circ} \mathrm{C}$.

O software ToupView (em microscópio estereoscópico com aumento de 6,3x) foi utilizado para captura de imagens para a medição de traqueídeos e o software Leica Application Suite para imagens (em microscópio com aumento de 400x), para medição de largura e diâmetro do lúmen. As medições foram feitas com o software Image, sendo 35 repetições de medições de comprimentos e 25 de larguras e diâmetros de lúmen para cada anel de crescimento (International Association of Wood Anatomists (IAWA, 1989).

Para informação da adequabilidade dos traqueídeos para produção de polpa e papel foram calculados os coeficientes indicativos de qualidade, tais como espessura da parede celular $(\mu \mathrm{m})$, fração da parede $(\%)$, coeficiente de flexibilidade (\%), índice de Runkel e índice de enfeltramento (Equações 3 a 7, respectivamente).

$$
\begin{aligned}
& E P=\left(\frac{L-D L}{2}\right) \\
& F P=\left(\frac{2 \cdot E P}{L}\right) \cdot 100 \\
& C F=\left(\frac{D L}{L}\right) \cdot 100 \\
& I R=\left(\frac{2 \cdot E P}{D L}\right) \\
& I E=\left(\frac{C}{\frac{L}{1000}}\right)
\end{aligned}
$$

Em que: $\mathrm{EP}=$ espessura da parede celular $(\mu \mathrm{m}) ; \mathrm{L}=$ largura dos traqueídeos $(\mu \mathrm{m}) ; \mathrm{DL}=$ diâmetro do lúmen $(\mu \mathrm{m}) ; \mathrm{C}$ $=$ comprimento dos traqueídeos $(\mathrm{mm}) ; \mathrm{CF}=$ coeficiente de flexibilidade (\%); IE = índice de enfeltramento; IR = índice de Runkel.

\section{Análise estatística}

Foi utilizada análise descritiva para a composição química e a densidade básica da madeira de $C$. lusitanica A análise de variância (ANOVA) foi aplicada para a morfologia dos traqueídeos no sentido medula-casca. Quando significativa, aplicou-se o teste de Tukey, em nível de $5 \%$ de probabilidade de erro, utilizando o software Sisvar.

\section{Resultados}

A densidade básica observada para a madeira de Cupressus lusitanica aos 16 anos de idade foi de $0,375 \mathrm{~g} \mathrm{~cm}^{-3}$ $\left( \pm 0,02 \mathrm{~g} \mathrm{~cm}^{-3}\right)$, podendo ser considerada leve ou de baixa densidade. A caracterização química da madeira de resultou em $2,13 \%( \pm 0,13)$ de extrativos, $0,27 \%$ ( \pm $0,07)$ de cinzas, $32,52 \%( \pm 0,15)$ de lignina e $65,08 \%$ ( \pm 0,23 ) de holocelulose (celulose + hemicelulose). 
Na Tabela 1 podem ser observados os valores médios referentes à morfologia dos traqueídeos da madeira de C. lusitanica.

Na Figura 1 pode se observada a variação das dimensões dos traqueídeos no sentido medula-casca, nos anéis de crescimento analisados, em relação ao comprimento, largura, diâmetro do lúmen e espessura da parede celular para a madeira de $C$. lusitanica.

Apenas o comprimento de fibras apresentou diferença estatística entre os anéis, sendo maior aos 16 anos, quando comparado com os traqueídeos da camada de crescimento referente aos 4 anos. Os demais parâmetros não diferiram estatisticamente, apesar de mostrarem uma tendência de elevação, com o aumento da idade (Figura 1).

Na Figura 2 são apresentados os valores e o comportamento dos índices de qualidade de polpa celulósica em relação aos anéis de crescimento da madeira de C. lusitanica. Para todos os parâmetros de qualidade de papel avaliados não se observou diferença estatística entre os anéis de crescimento.

Tabela 1. Dimensões médias dos traqueídeos da madeira Cupressus lusitanica.

Table 1. Average dimensions of the tracheids of Cupressus lusitanica wood.

\begin{tabular}{ccccc}
\hline Traqueídeos & $\begin{array}{c}\mathbf{C} \\
(\mathbf{m m})\end{array}$ & $\begin{array}{c}\mathbf{L} \\
(\boldsymbol{\mu m})\end{array}$ & $\begin{array}{c}\mathbf{D L} \\
(\boldsymbol{\mu m})\end{array}$ & $\begin{array}{c}\mathbf{E P} \\
(\boldsymbol{\mu m})\end{array}$ \\
\hline Mínimo & 1,55 & 26,91 & 21,77 & 2,38 \\
Máximo & 2,98 & 38,62 & 30,60 & 4,01 \\
Média & 2,41 & 31,40 & 25,15 & 3,12 \\
\hline $\mathrm{s}$ & 0,32 & 4,04 & 3,91 & 0,65 \\
\hline CV\% & 13,14 & 12,82 & 15,46 & 20,92 \\
\hline
\end{tabular}

Em que: $\mathrm{C}=$ comprimento; $\mathrm{L}=$ largura; $\mathrm{DL}=$ diâmetro do lúmen; $\mathrm{EP}=$ espessura da parede celular; $\mathrm{s}=$ desvio padrão; $\mathrm{CV}=$ coeficiente de variação.
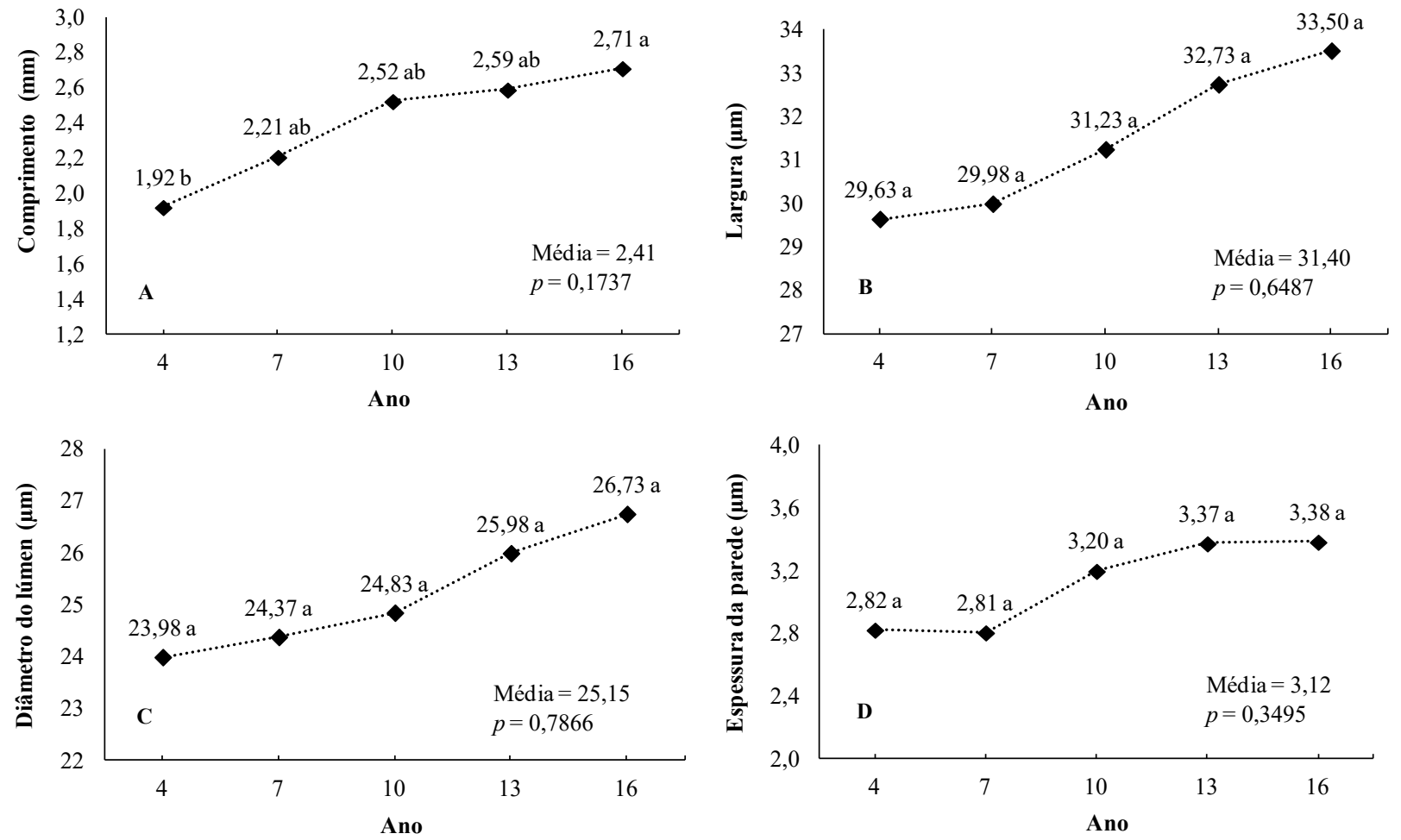

Figura 1. Dimensões dos traqueídeos no sentido medula-casca nas camadas de crescimento referentes aos 4, 7, 10, 13 e 16 anos. (A) Comprimento; (B) largura; (C) diâmetro do lúmen; (D) espessura da parede.

Figure 1. Tracheids dimensions from pith to bark in the growth rings from 4, 7, 10, 13 and 16 years old. (A) Length; (B) width; (C) lumen diameter; (D) wall thickness. 

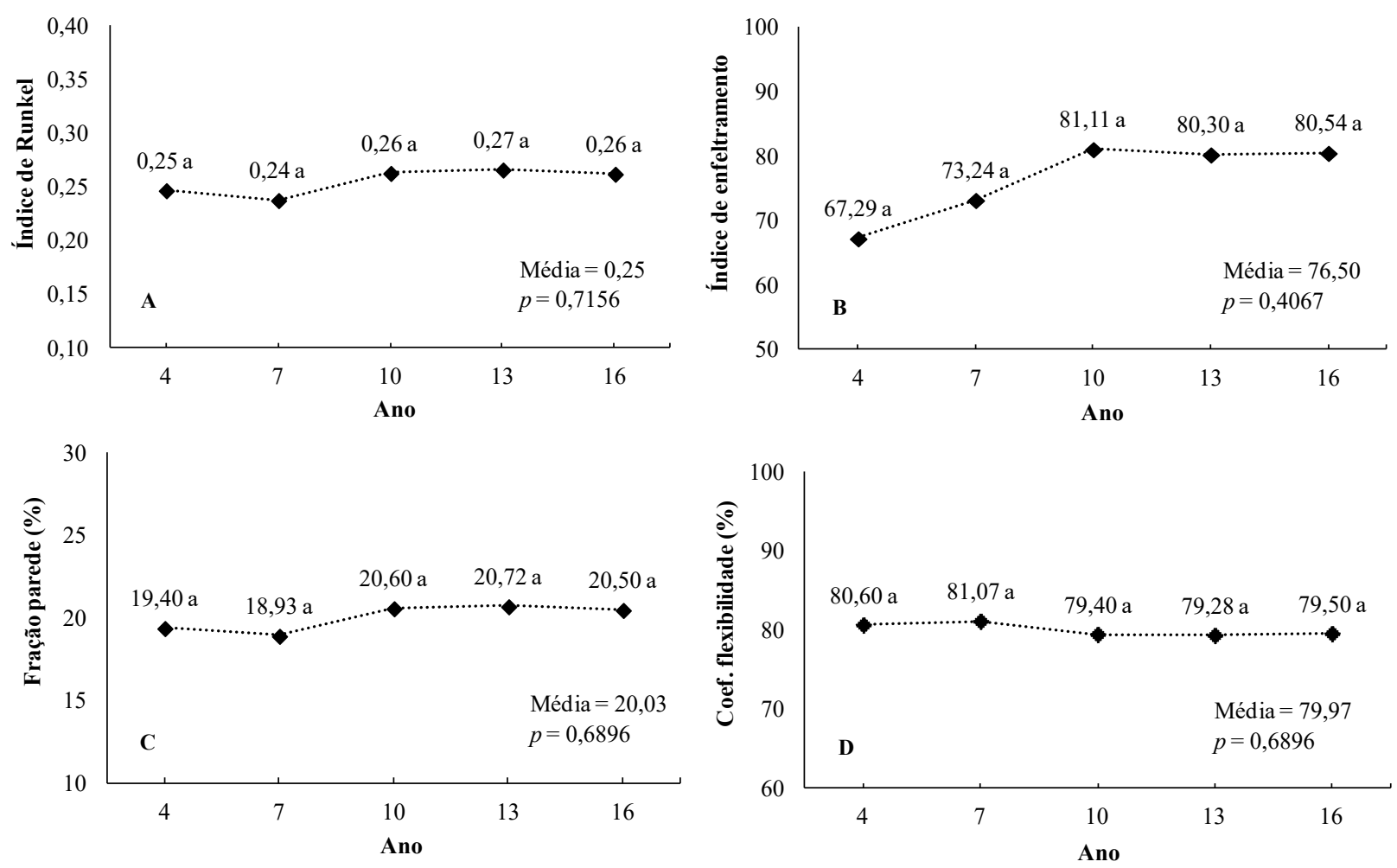

Figura 2. Parâmetros de qualidade de polpa nas camadas de crescimento referentes aos 4, 7, 10, 13 e 16 anos. (A) Índice de Runkel; (B) índice de enfeltramento; (C) fração parede (\%); (D) coeficiente de flexibilidade (\%).

Figure 2. Parameters of pulp quality in the growth rings from 4, 7, 10, 13 and 16 years old. (A) Runkel index; (B) felting index; (C) wall fraction (\%); (D) flexibility coefficient (\%).

\section{Discussão}

\section{Caracterização química e densidade básica da madeira}

A densidade básica observada para a madeira de Cupressus lusitanica $\left(0,375 \mathrm{~g} \mathrm{~cm}^{-3}\right)$ aos 16 anos foi inferior ao registrado na literatura para outras espécies de coníferas em idade próxima (Palermo et al., 2004; Andrade, 2006; Okino et al., 2006; Trianoski et al., 2013; Vivian et al., 2015; Almeida, et al., 2017), ou de árvores da mesma espécie, com 56 anos (Pereira \& Higa, 2003), como pode ser observado na Tabela 2. Portanto, pode-se considerar que a densidade básica alcançada por indivíduos desta espécie é sempre inferior ao registrado para espécies do gênero Pinus, tendo em vista a idade do material avaliado pelos referidos autores. $\mathrm{O}$ valor observado para a madeira de C. lusitanica está abaixo da faixa ideal de densidade citada por Burger \& Richter (1991) para produção de celulose, que varia de 0,4 a 0,6 $\mathrm{g} \mathrm{cm}^{-3}$. De acordo com Segura (2015), a densidade básica influencia diretamente nas etapas de produção de polpa celulósica, entre as quais se destacam a picagem dos cavacos, impregnação da madeira e cozimento, sendo considerado um parâmetro fundamental. Geralmente, madeiras com baixa densidade são mais fáceis de picar, impregnar e cozinhar, porém resultam em menos massa de polpa celulósica por cozimento.

Os valores observados de extrativos $(2,13 \%)$ e cinzas $(0,27 \%)$ podem ser considerados baixos, já o teor de lignina foi relativamente alto $(32,52 \%)$. O teor de holocelulose (celulose + hemicelulose $=65,08 \%$ ) está condizente com a literatura para as coníferas. Na Tabela 3 pode ser observada a comparação entre as espécies. 
Tabela 2. Comparação da densidade básica entre as espécies.

Table 2. Comparison of basic density between species.

\begin{tabular}{|c|c|c|c|}
\hline Espécie & $\begin{array}{l}\text { Idade } \\
\text { (anos) }\end{array}$ & $\begin{array}{c}\text { Densidade } \\
\text { básica }\left(\text { g.cm }^{-3}\right)\end{array}$ & Fonte \\
\hline C. lusitanica & 16 & 0,375 & $\begin{array}{l}\text { Vivian et al. } \\
\text { (2019)* }\end{array}$ \\
\hline C. lusitanica & 19 & 0,396 & Almeida (2017) \\
\hline C. lusitanica & 56 & 0,413 & $\begin{array}{l}\text { Pereira \& Higa } \\
\quad(2003)\end{array}$ \\
\hline C. glauca & 17 & 0,410 & Okino et al. (2006) \\
\hline P. taeda & 14 & 0,410 & Andrade (2006) \\
\hline P. taeda & 17 & 0,415 & $\begin{array}{l}\text { Trianoski et al. } \\
\text { (2013) }\end{array}$ \\
\hline P. taeda & 21 & 0,435 & Vivian et al. (2015) \\
\hline P. elliottii & 15 & 0,472 & $\begin{array}{l}\text { Palermo et al. } \\
\text { (2004) }\end{array}$ \\
\hline P. sylvestris & 45 & 0,436 & Vivian et al. (2015) \\
\hline
\end{tabular}

Tabela 3. Comparação da composição química entre as espécies.

Table 3. Comparison of chemical composition between species.

\begin{tabular}{|c|c|c|c|c|c|c|}
\hline Espécie & $\begin{array}{l}\text { Idade } \\
\text { (anos) }\end{array}$ & $\begin{array}{l}\text { TC } \\
(\%)\end{array}$ & $\begin{array}{l}\text { TE } \\
(\%)\end{array}$ & $\begin{array}{l}\text { TL } \\
(\%)\end{array}$ & $\begin{array}{l}\mathrm{HC} \\
(\%)\end{array}$ & Fonte \\
\hline C. lusitanica & 16 & 0,27 & 2,13 & 32,52 & 65,08 & $\begin{array}{l}\text { Vivian et al. } \\
\text { (2019)* }\end{array}$ \\
\hline C. lusitanica & 11 & 0,47 & - & 33,53 & 71,61 & $\begin{array}{c}\text { Foelkel \& } \\
\text { Zvinakevicius } \\
\text { (1981) }\end{array}$ \\
\hline C. lusitanica & 19 & 0,51 & 4,08 & 36,21 & 59,19 & $\begin{array}{l}\text { Almeida et al. } \\
\text { (2016) }\end{array}$ \\
\hline C. lusitanica & 56 & - & 7,50 & 29,90 & 62,60 & $\begin{array}{l}\text { Pereira \& Higa } \\
\quad(2003)\end{array}$ \\
\hline C. glauca & 17 & - & 1,1 & 32,00 & 75,90 & $\begin{array}{l}\text { Okino et al. } \\
\text { (2006) }\end{array}$ \\
\hline P. taeda & 16 & 0,36 & 3,65 & 29,83 & 66,17 & $\begin{array}{l}\text { Ampessan } \\
\text { (2015); } \\
\text { Ampessan et } \\
\text { al. (2015) }\end{array}$ \\
\hline P. taeda & 21 & - & 2,83 & 26,71 & 70,46 & $\begin{array}{l}\text { Vivian et al. } \\
\text { (2015) }\end{array}$ \\
\hline P. sylvestris & 45 & - & 6,40 & 25,61 & 67,99 & $\begin{array}{l}\text { Vivian et al. } \\
\quad(2015)\end{array}$ \\
\hline
\end{tabular}

Em que: $\mathrm{TC}=$ teor de cinzas; $\mathrm{TE}=$ teor de extrativos totais; $\mathrm{TL}=$ teor de lignina; $\mathrm{HC}=$ teor de holocelulose. ${ }^{*}$ Dados do presente artigo.

Segundo Freddo et al. (1999), os minerais podem ocasionar problemas no processo de polpação, tais como corrosões, incrustações e entupimentos nas tubulações, diminuindo sua vida útil. Desta forma, os $0,27 \%$ de cinzas é considerado um valor baixo de minerais, característica desejável no processo de polpação.
O teor de extrativos totais de C. lusitanica $(2,13 \%)$ se encontra dentro da amplitude estabelecida por Klock $\&$ Andrade (2013) para coníferas em geral $(5 \pm 3 \%)$. O valor observado para a madeira em estudo foi inferior a todas as utilizadas na comparação, com exceção de $C$. glauca, sendo um bom indicativo. Trugilho et al. (1996) atribuem a diferença desse constituinte às mudanças provocadas pelo processo de cernificação da madeira, no qual os extrativos são incorporados ao cerne.

A quantidade de extrativos influencia o rendimento de polpa celulósica, bem como interfere na quantidade de reagentes utilizados no processo. Além disso, a presença de extrativos é indesejável na fabricação de papel, pois pode acarretar a deposição de resinas, também denominadas de pitch (D'Almeida et al., 2013).

O teor de lignina encontrado para a espécie em estudo é relativamente alto para a polpação, estando próximo ao esperado para espécies de coníferas (entre 28 e $30 \%$, de acordo com Klock \& Andrade, 2013). A lignina age como um material cimentante entre os traqueídeos, dificultando a individualização dos mesmos no processo de polpação química, o que reduz o rendimento do cozimento (Celulose On-Line, 2019). Segundo Alves (2010), as operações de cozimento visam retirar a maior quantidade possível de lignina, sem danificar significativamente as fibras/traqueídeos, sendo que as madeiras com altos teores de lignina normalmente exigem maiores cargas de reagentes químicos para a deslignificação.

\section{Morfologia dos traqueídeos e seus indicadores de qualidade}

Os valores encontrados nesse estudo foram consoantes com os citados por outros autores para a madeira de $C$. lusitanica, porém inferiores quando comparados com as espécies de Pinus, (Tabela 4).

Em relação à variação radial das dimensões dos traqueídeos (Figura 1), apenas o comprimento apresentou diferença significativa. A madeira, de forma geral, apresenta boa homogeneidade, que pode trazer reflexos positivos frente aos processos industriais, fato que pode estar relacionado ao material genético avaliado, bem como às condições de crescimento e tratos silviculturais aplicados ao povoamento. Levando em consideração ainda o comprimento de traqueídeos (Figura 1A) pode-se inferir que a transição de madeira juvenil para adulta nos indivíduos avaliados tem início aos 10 anos de idade. De acordo com Foelkel et al. (1975), para tal parâmetro os 
elementos fibrosos localizados próximos à casca, tanto para coníferas quanto para folhosas, podem ser até duas vezes maiores que os encontrados perto da medula.

Tabela 4. Comparação da morfologia dos traqueídeos entre as espécies.

Table 4. Comparison of tracheid morphology among species.

\begin{tabular}{|c|c|c|c|c|c|c|}
\hline Espécie & $\begin{array}{l}\text { Idade } \\
\text { (anos) }\end{array}$ & $\begin{array}{c}\mathrm{C} \\
(\mathrm{mm})\end{array}$ & $\begin{array}{c}\mathrm{L} \\
(\mu \mathrm{m})\end{array}$ & $\begin{array}{c}\mathrm{DL} \\
(\mu \mathrm{m})\end{array}$ & $\begin{array}{c}\text { EP } \\
(\mu \mathrm{m})\end{array}$ & Fonte \\
\hline C. lusitanica & 16 & 2,41 & 31,40 & 25,15 & 3,12 & $\begin{array}{l}\text { Vivian et al. } \\
(2019)^{*}\end{array}$ \\
\hline C. lusitanica & 11 & 2,12 & 28,00 & - & 2,80 & $\begin{array}{c}\text { Foelkel \& } \\
\text { Zvinakevicius } \\
\text { (1981) }\end{array}$ \\
\hline C. lusitanica & 56 & 2,90 & 34,30 & - & 5,90 & $\begin{array}{c}\text { Pereira \& } \\
\text { Higa (2003) }\end{array}$ \\
\hline P. taeda & 9 & 3,61 & 41,67 & 30,63 & 5,52 & Gomes (2009) \\
\hline P. taeda & 16 & 3,71 & 41,35 & - & 6,54 & $\begin{array}{l}\text { Ampessan } \\
\text { (2015); } \\
\text { Ampessan et } \\
\text { al. (2015) }\end{array}$ \\
\hline P. taeda & 21 & 3,50 & 40,55 & 27,71 & 6,41 & $\begin{array}{l}\text { Vivian et al. } \\
\quad(2015)\end{array}$ \\
\hline P. elliottii & 30 & 3,70 & 47,23 & - & 7,64 & Muñiz (1993) \\
\hline P. sylvestris & 45 & 3,10 & 43,73 & 28,15 & 7,59 & $\begin{array}{c}\text { Vivian et al. } \\
\text { (2015) }\end{array}$ \\
\hline
\end{tabular}

Em que: $\mathrm{C}=$ comprimento; $\mathrm{L}=$ largura; $\mathrm{DL}=$ diâmetro do lúmen; $\mathrm{EP}=$ espessura da parede celular. *Dados do presente artigo.

Em comparação com os índices de qualidade da madeira de espécies de coníferas utilizadas no Brasil e no mundo, para produção de polpa celulósica (Tabela 5), a madeira de $C$. lusitanica possui qualidade superior à registrada para as madeiras de $P$. taeda e $P$. sylvestris (Gomes, 2009; Ampessan, 2015; Ampessan et al., 2015; Vivian et al., 2015). A madeira de C. lusitanica é superada apenas pelo índice de enfeltramento (que quanto maior, melhor será a ligação das fibras/ traqueídeos), refletindo em uma resistência inferior ao rasgo do papel produzido com esta matéria prima. Os demais indicadores apresentam bom potencial, com fração parede, coeficiente de flexibilidade e índice de Runkel dentro do recomendado para fabricação de papel.

Para o índice de Runkel, que avalia o grau de colapso dos traqueídeos durante o processo de produção de papel, busca-se valores baixos, pois quanto menor, maior será o grau de colapso, dando aos traqueídeos uma maior superfície de contato, o que resulta em uma resistência à tração e ao estouro ao papel. $\mathrm{O}$ valor obtido para a madeira de $C$. lusitanica foi de 0,25 ; valor este que admite enquadrá-la no grupo II - muito boa para produção de papel, segundo a classificação proposta por Runkel (1952). A Figura 2A demostra que quase não houve oscilação na linha de crescimento, tendo o ano 4 apresentado valor de 0,25 enquanto o ano 16 apresentou 0,26 .

Tabela 5. Comparação dos indicadores de qualidade entre as espécies.

Table 5. Comparison of quality indicators between species.

\begin{tabular}{|c|c|c|c|c|c|c|}
\hline Espécie & $\begin{array}{l}\text { Idade } \\
\text { (Anos) }\end{array}$ & $\begin{array}{l}\text { FP } \\
(\%)\end{array}$ & $\begin{array}{l}\text { CF } \\
(\%)\end{array}$ & IR & IE & Fonte \\
\hline C. lusitanica & 16 & 20,03 & 79,97 & 0,25 & 76,50 & $\begin{array}{c}\text { Vivian et al. } \\
(2019)^{*}\end{array}$ \\
\hline P. taeda & 9 & 26,49 & 73,51 & 0,36 & 86,63 & $\begin{array}{l}\text { Gomes } \\
(2009)\end{array}$ \\
\hline P. taeda & 16 & 29,98 & 70,02 & 0,47 & 93,44 & $\begin{array}{l}\text { Ampessan } \\
\text { (2015); } \\
\text { Ampessan et } \\
\text { al. (2015) }\end{array}$ \\
\hline P. taeda & 21 & 32 & 68 & 0,46 & 86 & $\begin{array}{l}\text { Vivian et al. } \\
\quad(2015)\end{array}$ \\
\hline P. sylvestris & 45 & 36 & 64 & 0,55 & 71 & $\begin{array}{l}\text { Vivian et al. } \\
\text { (2015) }\end{array}$ \\
\hline
\end{tabular}

Em que: $\mathrm{FP}=$ fração parede; $\mathrm{CF}=$ coeficiente de flexibilidade; $\mathrm{IR}=$ índice de Runkel; IE $=$ índice de enfeltramento. ${ }^{*}$ Dados do presente artigo.

O índice de enfeltramento relaciona o comprimento e a largura do traqueídeo, sendo que quanto maior o valor, maior será a resistência ao rasgo do papel. Dessa forma o valor encontrado para madeira de $C$. lusitanica $(76,50)$ confere uma boa resistência ao papel. O índice de enfeltramento (Figura 2B) exibiu um relativo aumento do ano $4(67,29)$ para o ano 10 $(81,11)$, característica positiva, visto que quanto maior o índice de enfeltramento maior será a resistência ao rasgo. Nos demais anos avaliados houve estabilização deste parâmetro: $13(80,30)$ e $16(80,54)$.

Para fração parede da espécie de $C$. lusitanica obtevese um valor médio de $20,03 \%$. Segundo Shimoyama \& Wiecheteck (1993), para valores abaixo de 40\% esperase uma alta resistência à tração e ao estouro, dando maior resistência ao papel. Desta forma, o valor encontrado para a espécie é considerado excelente. Como pode ser observado na Figura 2C os valores de fração parede não se alteraram significativamente com o passar dos anos, se mantendo próximo aos $20 \%$, o que é considerado ótimo.

Em relação ao coeficiente de flexibilidade, quanto maior o seu valor mais flexível serão os traqueídeos, ou seja, maior será a resistência à tração e ao estouro do papel (Gonçalez et al., 2014). Os traqueídeos do material estudado apresentaram um valor médio de $79,97 \%$, o que pode ser considerado muito bom. O coeficiente 
de flexibilidade (Figura 2D) se manteve praticamente estável durante os anos analisados.

A pouca variação entre os anéis de crescimento apresentada em $C$. lusitanica é uma característica de grande valia na produção de polpa celulósica, pois o papel apresentará uma homogeneidade, independente da porção de madeira utilizada, seja madeira juvenil ou adulta, de origem de desbastes ou mesmo de corte final.

\section{Conclusões}

A madeira de Cupressus lusitanica, aos 16 anos de idade, possui densidade inferior, baixo teor de extrativos e cinzas, porém, elevado teor de lignina em comparação ao registrado em espécies do gênero Pinus em idade semelhante.

Os parâmetros morfológicos avaliados não diferiram estatisticamente entre si, com exceção do comprimento dos traqueídeos ao longo do incremento em diâmetro da espécie, refletindo a homogeneidade do material avaliado.

Embora as dimensões dos traqueídeos da madeira de C. lusitanica tenham apresentado valores inferiores aos já relatados para espécies do gênero Pinus, os indicadores de qualidade de polpa celulósica foram superiores em praticamente todos os parâmetros avaliados.

C. lusitanica ainda não conta com um programa de melhoramento genético consolidado como o já existente para outras espécies de coníferas. Ainda assim, sua madeira na idade e condições de crescimento avaliadas apresentou boas características tecnológicas para produção de celulose e papel, devendo ter uma atenção apenas com a densidade e o teor de lignina, visto a influência negativa no rendimento do processo e consumo de reagentes, respectivamente.

\section{Referências}

ABNT. Associação Brasileira de Normas Técnicas. NBR 11.941: madeira: determinação da densidade básica. Rio de Janeiro, 2003. 6 p.

Almeida, C. C. F. et al. Applicability evaluation of Cupressus lusitanica for pulp production. Maderas, Ciencia y Tecnologia, v. 18 , n. 4 , p. 651-662, 2016. http://dx.doi.org/10.4067/S0718$221 \mathrm{X} 2016005000057$.

Almeida, C. C. F. et al. Avaliação da qualidade da colagem de topo da madeira de Cupressus lusitanica Mill. para a produção de painéis colados lateralmente. Scientia Forestalis, v. 45, n. 113, p. 9-19, 2017. http://www.dx.doi.org/10.18671/scifor.v45n113.01.
Alves, I. C. N. Potencial da madeira de Eucalyptus benthamii Maiden et Cambage visando à produção de celulose kraft. 2010. 62 f. Dissertação (Mestrado em Ciência Florestal) - Universidade Federal de Viçosa, Viçosa, MG.

Ampessan, C. G. M. et al. Otimização do tempo de estocagem de cavacos de Pinus taeda e Pinus elliottii para a produção de celulose e papel. Scientia Forestalis, v. 43, n. 108, p.885-893, 2015. http:// dx.doi.org/10.18671/scifor.v43n108.13.

Ampessan, C. G. M. Idade da madeira na qualidade da polpa e do papel. 2015. 134 f. Dissertação (Mestrado em Engenharia Florestal) - Universidade do Estado de Santa Catarina, Lages.

Andrade, A. S. Qualidade da madeira, celulose e papel em Pinus taeda L.: influência da idade e classe de produtividade. 2006. 107 f. Dissertação (Mestrado em Engenharia Florestal) - Universidade Federal do Paraná, Curitiba.

Burger, L. M. \& Richter, H. G. Anatomia da madeira. São Paulo: Nobel, 1991. 154 p.

Celulose On-Line. Introdução ao processo de obtenção de celulose. Disponível em: <http://www.crq4.org.br/sms/files/file/dc417.pdf>. Acesso em: 17 jan. 2019.

D’Almeida, M. L. O. et al. Celulose. São Paulo: Senai-SP, 2013. $352 \mathrm{p}$.

Favero, C. et al. Aspectos gerais do processo de pré-branqueamento de celulose. Enciclopédia Biosfera, v. 10, n. 18, p. 36-96, 2014.

Foelkel, C. E. B. et al. Variabilidade no sentido radial de madeira de Pinus elliottii. IPEF, n. 10, p. 1-11, 1975.

Foelkel, C. \& Zvinakevicius, C. Coníferas exóticas aptas para produção de celulose kraft: Cupressus lusitanica. 1981. Disponível em: <http://www.celso-foelkel.com.br/artigos/1981_Cupressus_ lusitanica.pdf $>$. Acesso em: 17 jan. 2019.

Freddo, A. et al. Elementos minerais em madeiras de eucaliptos e acácia negra e sua influência a indústria de celulose kraft branqueada. Ciência Florestal, v. 9, n. 1, p. 193-209, 1999.

Frinhani, E. M. D. \& Daltoé, R. Comparação das propriedades físicomecânicas de polpas celulósicas Kappa 45 e Kappa 100 destinada à fabricação de papéis para embalagens rígidas. Unoesc \& Ciência: Acet, v. 3, n. 1, p. 65-74, 2012.

Gomes, F. A. Avaliação dos processos Kraft convencional e Lo-Solids para madeira de Pinus taeda. 2009. 99 f. Dissertação (Mestrado em Química Industrial) - Escola Superior de Agricultura Luiz de Queiroz, Piracicaba.

Gonçalez, J. C. et al. Relações entre dimensões de fibras e de densidade da madeira ao longo do tronco de Eucalyptus urograndis. Scientia Forestalis, v. 42, n. 101, p. 81-89, 2014.

IAWA. International Association of Wood Anatomists. List of microscopic features for hardwood identification. IAWA Bulletin, v. 10, n. 3, p. 219-332, 1989.

Ibá. Indústria Brasileira de Árvores. Relatório 2019: ano base 2018. São Paulo, 2019. 80 p.

Klock, U. \& Andrade, A. S. Química da madeira. 4. ed. Curitiba, 2013. $87 \mathrm{p}$. 
Muñiz, G. I. B. Caracterização e desenvolvimento de modelos para estimar as propriedades e o comportamento na secagem da madeira de Pinus elliottii Engelm. e Pinus taeda L. 1993. 252 f. Tese (Doutorado em Ciências Florestais) - Universidade Federal do Paraná, Curitiba.

Okino, E. Y. A. et al. Descrição dos caracteres tecnológicos da madeira de Cupressus glauca Lam. wood characteristics. Scientia Forestalis, n. 72, p. 39-48, 2006.

Palermo, G. P. et al. Determinação da densidade da madeira de Pinus elliottii Engelm, através de atenuação de radiação gama comparada a métodos tradicionais. Floresta e Ambiente, v. 11, n.1, p. 1-6, 2004.

Pereira, J. C. D. \& Higa, R. C. V. Propriedades da madeira de Cupressus lusitanica Mill. Colombo: Embrapa Florestas, 2003. 5 p. (Embrapa Florestas. Comunicado técnico, 107). Disponível em: http://ainfo.cnptia.embrapa.br/digital/bitstream/CNPF-200909/35567/1/Com_tec107.pdf.

Segura, T. E. S. Avaliação das madeiras de Corymbia citriodora, Corymbia torelliana e seus híbridos visando à produção de celulose kraft branqueada. 2015. $198 \mathrm{f}$. Tese (Doutorado em Recursos Florestais) - Escola Superior de Agricultura "Luiz de Queiroz", Piracicaba.
Shimizu, J. Y. et al. Desempenho de progênies de cipreste em Rio Negrinho-SC. In: CONGRESSO BRASILEIRO DE MELHORAMENTO DE PLANTAS, 6., 2011, Búzios. Panorama atual e perspectivas do melhoramento de plantas no Brasil. [Búzios]: SBMP, 2011.

Shimoyama, V. R. S. \& Wiecheteck, M. S. S. Características da madeira e da pasta termomecânica de Pinus patula var. tecunumanii para produção de papel imprensa. IPEF, v. 9, n. 27, p. 63-80, 1993.

Tappi. Technical Association of Pulp and Paper Industry. Test Methods. Atlanta, 2007. 2 v.

Trianoski, R. et al. Avaliação da estabilidade dimensional de espécies de pinus tropicais. Floresta eAmbiente, v. 20, n. 3, p. 398-406, 2013. http://dx.doi.org/10.4322/floram.2012.071.

Trugilho, P. F. et al. Influência da idade nas características físicoquímicas e anatômicas da madeira de Eucalyptus saligna. Cerne, v. 2, n. 1, p. 94-111, 1996.

Vivian, M. A. et al. Qualidade das madeiras de Pinus taeda e Pinus sylvestris para a produção de polpa celulósica kraft. Scientia Forestalis, v. 48, n. 105, p. 183-191, 2015. 